\title{
Pasteurella avium (Hinz and Kunjara 1977) comb. nov. and Pasteurella volantium sp. nov.
}

\author{
R. MUTTERS, ${ }^{1 *}$ K. PIECHULLA, ${ }^{1}$ K.-H. HINZ, ${ }^{2}$ AND W. MANNHEIM ${ }^{1}$
}

Zentrum für Hygiene und Medizinische Mikrobiologie der Philipps-Universität, Abteilung Bakteriologie, Pilgrimstein 2, D-3550 Marburg, ${ }^{1}$ and Institute for Poultry Disease, The School of Veterinary Medicine, D-3000 Hannover, ${ }^{2}$ Federal Republic of Germany

\begin{abstract}
A deoxyribonucleic acid-deoxyribonucleic acid hybridization study (spectrophotometric method) showed that the species Haemophilus avium Hinz and Kunjara 1977 is composed of three deoxyribonucleic acid homology groups; these three groups are genetically closer to Pasteurella multocida, the type species of the genus Pasteurella, than to Haemophilus influenzae, the type species of the genus Haemophilus. We propose to transfer the species Haemophilus avium to the genus Pasteurella as Pasteurella avium comb. nov. (type strain, ATCC 29546) and to change the circumscription of this taxon to include only strains that are unable to ferment L-arabinose, maltose, and mannitol and unable to hydrolyze $o$-nitrophenyl- $\beta$-D-galactopyranoside. The name Pasteurella volantium sp. nov. (type strain, NCTC 3438) is proposed for strains (formerly identified as $H$. avium) that are unable to ferment $\mathrm{L}$-arabinose and are able to ferment maltose and mannitol and to hydrolyze $o$-nitrophenyl- $\beta$-D-galactopyranoside. A third unnamed species consists of former $H$. avium strains that are able to ferment $L$-arabinose.
\end{abstract}

Hinz and Kunjara (6) classified V-factor (nicotinamide adenine dinucleotide [NAD])-dependent avian haemophili which were different from Haemophilus paragallinarum as Haemophilus avium. These organisms can be isolated from chickens and other fowl (4). Unlike $H$. paragallinarum, $H$. avium is not involved in the pathogenesis of a specific disease of chickens, coryza infectiosa gallinarum. Most strains of $H$. avium appear to be harmless mucosal commensal organisms which are spread via direct contact or airborne transmission (5), but with some of the $\mathbf{L}$-arabinose-fermenting strains marked serofibrinous infraorbital sinusitis and edema of the face and, in some cases, of the wattles have been produced in chickens after inoculation into the submucosa of the infraorbital sinus (Hinz, unpublished data). The phenotypic diversity among a series of $H$. avium strains studied motivated us to determine their genetic interrelationships and their taxonomic positions in the family Pasteurellaceae Pohl $1981(11,16)$. Our results indicated that the species $H$. avium is genetically heterogeneous and can be separated into three groups which are phenotypically distinguishable. We propose to transfer the former species $H$. avium to the genus Pasteurella and to split it into the following three species: Pasteurella avium sensu stricto, Pasteurella volantium sp. nov., and a third unnamed species.

\section{MATERIALS AND METHODS}

Microorganisms. The bacterial strains investigated are listed in Table 1. They were propagated on chocolate agar (tryptic soy agar [Difco Laboratories, Detroit, Mich.] supplemented with $5 \%$ [vol/vol] defibrinated sheep blood and heated to $80^{\circ} \mathrm{C}$ for $15 \mathrm{~min}$ before pouring), purified by subculturing typical single colonies, and stored in the lyophilized state until needed.

Phenotypic characterization. Both the identification methods of Kilian and Frederiksen (8) and those of Mannheim et al. (12) were used. Acinetobacter sp. strain HIH ST661/60 served to supply V-factor, as described by Mannheim (9). The media used for testing the metabolism of selected amino

\footnotetext{
* Corresponding author.
}

acids were supplemented with NAD to a final concentration of $1 \mu \mathrm{g} / \mathrm{ml}$.

Preparation of DNA. Deoxyribonucleic acid (DNA) was prepared by the method of De Ley et al. (2) from cells of the early stationary phase of growth, which were harvested from aerated cultures grown at $35^{\circ} \mathrm{C}$.

DNA base composition and molecular weight of genome DNA. Thermal denaturation midpoints were used to determine the guanine-plus-cytosine $(\mathrm{G}+\mathrm{C})$ contents of the DNAs (2). Escherichia coli B (NCTC 10537) DNA served as a reference $(\mathrm{G}+\mathrm{C}$ content, $52 \mathrm{~mol} \%)$. The molecular weights of genome DNAs were calculated from initial renaturation rates by the method of Gillis et al. (3).

DNA-DNA hybridization. Initial renaturation rates for homologous and heterologous reassociations were determined by the method of De Ley et al. (2), as described previously $(13,15,17)$.

\section{RESULTS AND DISCUSSION}

Phenotypic features. The 19 strains of $H$. avium studied fit the description of the family Pasteurellaceae Pohl 1981 (11). They were gram negative, nonmotile, and coccoid to rod shaped and contained demethylmenaquinones (always) and ubiquinones (usually) but no menaquinones (10). They were nonhemolytic, showed no colonial adherence, and formed smooth colonies $2.5 \mathrm{~mm}$ in diameter after $24 \mathrm{~h}$ of growth on chocolate agar. No growth occurred on MacConkey agar or in Simmons citrate medium. All strains except the ornithine decarboxylase-negative type of Bisgaard taxon 13 (E. B. Madsen, M. Bisgaard, R. Mutters, and K. B. Pedersen, Can. J. Comp. Med., in press), represented by strain K117, required V-factor. Nitrates were reduced to nitrites. Prompt positive reactions were observed for $N, N, N^{\prime}, N^{\prime}$-tetramethyl1,4-phenylenediamine hydrochloride oxidase, catalase, alkaline phosphatase, and acid production without gas from D-glucose, D-galactose, D-mannose, D-fructose, sucrose, and trehalose. Negative results were obtained for indole production, hydrolysis of urea and arginine, decarboxylation of lysine, liquefaction of gelatin, and acid production from L-sorbose, L-rhamnose, starch, salicin, esculin, adonitol, dulcitol, and meso-inositol. 
As shown in Table 2, the $H$. avium strains studied and some other strains could be separated phenotypically into three groups on the basis of their different capabilities for catabolizing $\mathrm{L}$-arabinose, maltose, and mannitol and by the $o$-nitrophenyl- $\beta$-D-galactopyranoside test. All of the reference strains used in this study could be separated from these three groups by using an appropriate set of biochemical reactions, as described previously $(12,14)$.

Base compositions and molecular weights of genome DNAs. As shown in Table 1, no significant differences in the $\mathrm{G}+\mathrm{C}$ contents and the genome sizes of the DNAs of the three groups of $H$. avium were found; these values ranged from 43 to $47 \mathrm{~mol} \%$ and from $1.5 \times 10^{9}$ to $2.1 \times 10^{9}$ daltons, respectively.

DNA reassociation. On the basis of DNA binding values (Tables 3 through 5), the strains of $H$. avium studied could be divided into three groups, which were identical to those mentioned above and should receive the rank of species as compared with the genetic relatedness in well-established Pasteurellaceae species.

Our experience with the renaturation method of DNA hybridization has shown that well-defined species of the Pasteurellaceae exhibit high degrees of DNA homology (i.e., at or above $85 \%$ binding) $(13,17)$. Therefore, discrimination of closely related species may be impaired by the error in the renaturation method and may require taxometric evaluation of the data. Ultimately, the recognition of species remains a matter of convention.

The strains representing the first $H$. avium group proved to be highly related mutually and exhibited DNA binding values of about $80 \%$ with two Pasteurella strains that are as yet unclassified on the species level (strains NCTC 11623

TABLE 1. Bacterial strains used in this study

\begin{tabular}{|c|c|c|c|c|c|c|}
\hline $\begin{array}{c}\text { Strain } \\
\text { designation in } \\
\text { this study }{ }^{a}\end{array}$ & Received as: & Other strain no." & $\begin{array}{l}\text { Isolated } \\
\text { from: }\end{array}$ & $\begin{array}{l}\text { Country of } \\
\text { isolation }^{h}\end{array}$ & $\begin{array}{c}\mathrm{G}+\mathrm{C} \\
\text { content } \\
(\mathrm{mol} \%)^{c}\end{array}$ & $\begin{array}{l}\text { Genome } \\
\text { mol wt } \\
\left(\times 10^{9}\right)^{d}\end{array}$ \\
\hline NCTC $4189^{\mathrm{T}}$ & A. lignieresii & L. Thompson 1 & Cattle & USA & 44.2 & 1.8 \\
\hline NCTC $5906^{\mathrm{T}}$ & H. aphrophilus & O. Khairat 320 & Human & USA & 44.5 & 1.5 \\
\hline ATCC $29546^{\mathrm{T}}$ & H. avium & K.-H. Hinz IPDH 2654 & Chicken & USA & 44.7 & 1.9 \\
\hline HIM 789-1 & H. avium & K.-H. Hinz IPDH 1762 & Chicken & FRG & 45.9 & 2.1 \\
\hline HIM 789-2 & H. avium & K.-H. Hinz IPDH 94 & Chicken & FRG & 44.0 & 1.8 \\
\hline HIM 789-3 & H. avium & K.-H. Hinz IPDH 0003 & Chicken & FRG & 44.7 & 1.8 \\
\hline HIM 789-4 & H. avium & K.-H. Hinz IPDH 0002 & Chicken & FRG & 44.3 & 1.9 \\
\hline HIM 789-5 & H. avium & K.-H. Hinz IPDH 280 & Chicken & FRG & 45.4 & 1.7 \\
\hline HIM 789-6 & H. avium & K.-H. Hinz IPDH 306 & Chicken & FRG & 44.2 & 1.7 \\
\hline HIM 859-1 & H. avium & K.-H. Hinz IPDH $219-74$ & Turkey & FRG & & \\
\hline HIM 841-3 & H. avium & K.-H. Hinz IPDH 207 & Chicken & USA & & \\
\hline HIM 841-1 & H. avium & K.-H. Hinz IPDH 167-79 & Peacock & FRG & & \\
\hline HIM 859-3 & H. avium & K.-H. Hinz IPDH 780 & Chicken & FRG & & \\
\hline HIM 859-7 & H. avium & K.-H. Hinz IPDH 331-76 & Chicken & FRG & & \\
\hline HIM 860-2 & H. avium & K.-H. Hinz IPDH 712-76 & Chicken & FRG & & \\
\hline HIM 838-1 & H. avium & K.-H. Hinz IPDH 1254-70 & Chicken & FRG & & \\
\hline HIM 859-4 & H. avium & K.-H. Hinz IPDH 1103-77 & Chicken & FRG & & \\
\hline HIM 838-4 & H. avium & K.-H. Hinz IPDH 504-79 & Pigeon & FRG & & \\
\hline NCTC 3438 & $\begin{array}{c}\text { "Haemophilus } \\
\text { gallinarium" }\end{array}$ & R. Lovell 6 & Fowl & UK & 43.8 & 1.5 \\
\hline NCTC $8143^{\mathrm{T}}$ & H. influenzae & A. B. Rosher 680 & Human & USA & 38.8 & 1.2 \\
\hline ATCC $29545^{\mathrm{T}}$ & H. paragallinarum & K.-H. Hinz IPDH 2403 & Chicken & FRG & 42.3 & 1.7 \\
\hline NCTC $7857^{\mathrm{T}}$ & H. parainfluenzae & A. B. Rosher & Human & UK & 39.5 & 1.4 \\
\hline HIM 793-8 & $\begin{array}{l}\text { H. parainfluenzae } \\
\text { biotype } 1\end{array}$ & M. Kilian HK128 & Human & Denmark & 41.7 & 1.4 \\
\hline CCM $5869^{\mathrm{T}}$ & $\begin{array}{l}\text { Actinobacillus } \\
\quad \text { pleuropneumoniae }\end{array}$ & R. E. Shope 4074 & Swine & & 43.2 & 1.5 \\
\hline HIM 734-5 & $\begin{array}{l}\text { Haemophilus } \\
\quad \text { somnus }\end{array}$ & L. Corboz 719 & Bovine & Switzerland & 37.5 & 1.4 \\
\hline NCTC 4101 & Haemophilus sp. & A. Fleming 1 & Human & UK & 44.6 & 1.9 \\
\hline HIM 716-7 & Haemophilus sp. & K.-H. Hinz IPDH 2176 & Kestrel & FRG & 43.8 & 1.5 \\
\hline HIM 716-4 & Haemophilus sp. & K.-H. Hinz IPDH 195 & Budgerigar & FRG & 38.1 & 1.7 \\
\hline HIM 700-8 & Haemophilus sp. & K.-H. Hinz IPDH 312 & Pigeon & FRG & 37.0 & 1.7 \\
\hline ATCC $13361^{\mathrm{T}}$ & P. gallinarum & K. L. Heddleston USDA P-913 & Chicken & USA & 43.6 & 1.6 \\
\hline ATCC 13360 & P. gallinarum & K. L. Heddleston USDA P-892 & Chicken & USA & 43.7 & 1.6 \\
\hline NCTC $10322^{\mathrm{T}}$ & P. multocida & G. R. Carter W-9217 & Bovine & Canada & 41.6 & 1.6 \\
\hline SSI P614 & P. multocida & S. Namioka TS 8 & Chicken & Vietnam & 40.9 & 1.6 \\
\hline NCTC 11623 & Pasteurella sp. & J. E. Smith 166 & Dog & UK & 42.2 & 1.5 \\
\hline NCTC 11624 & Pasteurella sp. & W. Mannheim PE 4 & Cat & FRG & 40.4 & 1.5 \\
\hline HIM 844-2 & Pasteurella sp. & M. Bisgaard K117, taxon 13 & Calf & Denmark & 42.8 & 1.9 \\
\hline NCTC 11411 & Pasteurella sp. & M. Bisgaard F73, taxon 4 & Chicken & Denmark & 43.9 & 1.7 \\
\hline HIM $745-4$ & Pasteurella sp. & M. Bisgaard F279, taxon 1 & Duck & Denmark & 42.3 & 1.8 \\
\hline
\end{tabular}

${ }^{a}$ ATCC, American Type Culture Collection, Rockville, Md.; CCM, Czechoslovak Collection of Microorganisms, Brno, Czechoslovakia; HIM, Zentrum für Hygiene und Medizinische Mikrobiologie, Marburg. Federal Republic of Germany; IPDH. Institute for Poultry Disease, Hannover, Federal Republic of Germany; NCTC, National Collection of Type Cultures, Central Public Health Laboratory, London, England; SSI. Statens Seruminstitut, Copenhagen, Denmark.

${ }^{b}$ USA, United States of America; FRG, Federal Republic of Germany; UK, United Kingdom.

'Average of nine assays.

${ }^{d}$ Average of 6 to 12 assays. 
TABLE 2. Biochemical characteristics that distinguish the three species considered

\begin{tabular}{|c|c|c|c|c|c|c|c|c|c|}
\hline \multirow{3}{*}{ Strain $^{a}$} & \multicolumn{9}{|c|}{ Test results" } \\
\hline & \multicolumn{6}{|c|}{ Acid produced from: } & \multirow{2}{*}{$\begin{array}{c}\text { ONPG } \\
\text { hydrolyzed }\end{array}$} & \multirow{2}{*}{$\begin{array}{c}\text { Ornithine } \\
\text { decarboxylated }\end{array}$} & \multirow{2}{*}{$\begin{array}{l}\text { NAD } \\
\text { required }\end{array}$} \\
\hline & L-Arabinose & Maltose & Mannitol & Sorbitol & D-Xylose & Lactose & & & \\
\hline \multicolumn{10}{|c|}{$P$. avium sensu stricto } \\
\hline ATCC $29546^{\mathrm{T}}$ & - & - & - & - & - & - & - & - & + \\
\hline HIM 789-4 & - & - & - & - & + & - & - & - & + \\
\hline HIM 844-2 & - & - & - & - & + & - & - & - & - \\
\hline \multicolumn{10}{|c|}{$P$. volantium sp. nov. } \\
\hline HIM 789-3 & - & + & + & + & + & w & + & - & + \\
\hline HIM $859-1^{d}$ & - & + & + & + & - & w & + & - & + \\
\hline NCTC $3438^{\mathrm{T}}$ & - & + & + & - & + & - & + & - & + \\
\hline HIM $841-3^{d}$ & - & + & + & - & + & w & + & - & + \\
\hline HIM 841-1 ${ }^{d}$ & - & + & + & - & + & w & + & - & + \\
\hline HIM 859-3 ${ }^{d}$ & - & + & + & - & + & w & + & - & + \\
\hline HIM $859-7^{d}$ & - & + & + & - & - & - & + & - & + \\
\hline HIM $860-2^{d}$ & - & + & + & - & - & - & + & - & + \\
\hline NCTC 4101 & - & + & + & + & - & - & + & + & + \\
\hline HIM $838-1^{d}$ & - & + & + & + & - & - & + & + & + \\
\hline \multicolumn{10}{|c|}{ Pasteurella species A } \\
\hline HIM $789-5$ & + & - & + & - & - & - & - & - & + \\
\hline HIM $859-4^{d t}$ & + & - & + & - & - & - & - & - & + \\
\hline HIM 789-2 & + & - & + & - & + & w & + & - & + \\
\hline HIM 838-4 & + & + & - & - & + & - & - & - & + \\
\hline HIM 789-1 & $(+)$ & + & - & - & - & - & + & - & + \\
\hline \multicolumn{10}{|c|}{ Other Pasteurella spp. } \\
\hline HIM 789-6 & + & + & - & - & - & - & + & - & + \\
\hline NCTC 11623 & - & - & - & - & - & - & - & - & - \\
\hline NCTC 11624 & - & - & - & - & - & - & - & - & - \\
\hline
\end{tabular}

a Species assignments based on DNA-DNA hybridization results.

$b+$, Positive; $(+)$, positive within 48 to $72 \mathrm{~h} ; \mathrm{w}$, only weak reaction observed; - , negative.

' ONPG, $o$-Nitrophenyl- $\beta$-D-galactopyranoside.

${ }^{d}$ Strain not tested for DNA relatedness.

and NCTC 11624) (Table 3). These strains were related to the genus Pasteurella via Pasteurella multocida biotype 6, with DNA binding levels of approximately $55 \%$, and via the Pasteurella pneumotropica type Henriksen-Pasteurella

TABLE 3. Levels of DNA relatedness of P. avium strain ATCC $29546^{\mathrm{T}}$ with selected members of the Pasteurellaceae

\begin{tabular}{llc}
\hline \multicolumn{1}{c}{ Species } & \multicolumn{1}{c}{ Strain } & $\begin{array}{c}\text { \% Homology with strain } \\
\text { ATCC 29546 } \\
\text { (unless otherwise stated) }\end{array}$ \\
\hline P. avium & ATCC 29546 & 100 \\
$P$. avium & HIM 789-4 & $100(2.9)^{a}$ \\
$P$. avium & HIM 844-2 & $88(1.7)$ \\
Pasteurella sp. & NCTC 11624 & $78(7.9)$ \\
Pasteurella sp. & NCTC 11623 & $74(5.5)^{b}$ \\
$P$. gallinarum & ATCC 13360 & $61(1.2)$ \\
$P$. volantium & NCTC 3438 & $60(3.0)$ \\
$P$. gallinarum & ATCC 13361 & $52(6.2)$ \\
Pasteurella species A & HIM 789-1 & $38(4.0)$ \\
Pasteurella species A & HIM 789-5 & $36(7.6)$ \\
Pasteurella species A & HIM 789-2 & $35(4.0)^{\mathrm{C}}$ \\
Haemophilus sp. & HIM 700-8 & $31(1.5)$ \\
$P$. multocida & NCTC 10322 & $22(8.4)$ \\
Pasteurella sp. & HIM 789-6 & $20(2.3)$ \\
H. influenzae & NCTC 8143 & $9(2.8)$ \\
Haemophilus sp. & HIM 716-7 & $9(6.7)$ \\
Haemophilus sp. & HIM 716-4 & $7(2.5)$ \\
A. lignieresii & NCTC 4189 & $7(4.2)$ \\
Pasteurella sp. & NCTC 11411 & $2(3.1)$ \\
\hline
\end{tabular}

\footnotetext{
${ }^{a}$ The values in parentheses are standard deviations.

${ }^{b}$ Tested with $\boldsymbol{P}$. avium strain HIM $789-4$ instead of strain ATCC $29546^{\mathrm{T}}$. When $P$. avium strain HIM 844-2 was tested instead of strain HIM 789-4, the level of DNA homology was $81 \%$ (standard deviation, $4.2 \%$ ).

" Tested with $P$. avium strain HIM $789-4$ instead of strain ATCC $29546^{\mathrm{T}}$
}

"gas" group, with binding levels of 59 and $57 \%$ (Mutters, unpublished data), which is related to $P$. multocida at the $60 \%$ DNA homology level (Mutters, unpublished data). Furthermore, this group is linked to the genus Pasteurella via Pasteurella volantium (see below). A direct comparison of $H$. avium ATCC $29546^{\mathrm{T}}$ (T = type strain) and $P$. multocida NCTC $10322^{\mathrm{T}}$ yielded only $22 \%$ DNA binding, the level of DNA binding with the type species of Haemophilus (Haemophilus influenzae NCTC $8143^{\mathrm{T}}$ ) was $9 \%$, and the level of DNA binding with the type species of Actinobacillus (Actinobacillus lignieresii NCTC $4189^{\mathrm{T}}$ ) was $7 \%$ (i.e., below the reliability of the renaturation method) (2). On the basis of these DNA relationships, the group containing the type strain of $H$. avium clearly belongs to the genus Pasteurella and must be reclassified as Pasteurella avium. A determination of the relationships of Pasteurella sp. strains NCTC 11623 and NCTC 11624 to $P$. avium will require more detailed investigations with more strains. Phenotypically, these strains can be separated from $P$. avium only by their ability to produce indole and their somewhat lower $\mathrm{G}+\mathrm{C}$ contents (40 to $43 \mathrm{~mol} \%$ ).

The second group studied, for which we propose the name Pasteurella volantium, proved to be related to $P$. avium at the $60 \%$ DNA binding level. On the other hand, it was linked to Pasteurella gallinarum by DNA binding values of about $70 \%$ and was linked by DNA relatedness values of 57 and $49 \%$ to another new Pasteurella species from chickens, namely, Bisgaard taxon 4 (1), represented by strain NCTC 11411 (Table 4). A DNA binding level of 59\% was determined with $P$. multocida NCTC $10322^{\mathrm{T}}$. DNA binding values below $40 \%$ have been observed for $P$. volantium with Haemophilus aegyptius ATCC $11116^{\mathrm{T}}$, Haemophilus aphrophilus NCTC $5886^{\mathrm{T}}$, Haemophilus haemoglobino- 
philus NCTC $1659^{\mathrm{T}}$, Haemophilus influenzae NCTC 4560 , Haemophilus paragallinarum ATCC $29545^{\mathrm{T}}$, Haemophilus parahaemolyticus ATCC $10014^{\mathrm{T}}$, Haemophilus parainfuenzae NCTC $7857^{\mathrm{T}}$, and ATCC 7901, Haemophilus parasuis NCTC $4557^{\mathrm{T}}$, Actinobacillus seminis ATCC $15768^{\mathrm{T}}$, Actinobacillus sp. strain ATCC 27072, Pasteurella haemolytica NCTC $9380^{\mathrm{T}}$ and NCTC 11610 , Pasteurella pneumotropica type Jawetz strain NCTC 8284, Pasteurella pneumotropica type Heyl strain ATCC 12555, Pasteurella ureae NCTC $10219^{\mathrm{T}}$, Pasteurella sp. ("Pasteurella bettii") strain NCTC 10535, and Pasteurella sp. strain NCTC 10699 (S. Pohl, Ph.D. thesis, Philipps-Universität, Federal Republic of Germany, Marburg, 1979; S. Pohl, unpublished data).

The third group of former $H$. avium strains consists of Ł-arabinose-fermenting strains. This group was shown to be remote from both of the other groups, with DNA binding values of less than $40 \%$, but was also included in the genus Pasteurella on the basis of DNA relatedness values with $P$. gallinarum ranging from 63 to $67 \%$ (Table 5). We suggest that this species remain unnamed until its exact taxonomic position within the genus Pasteurella can be determined by studying more strains.

Our data contain strong evidence that the three groups of $H$. avium should be classified as distinct species of the genus Pasteurella.

The incorporation of $\mathrm{V}$-factor-dependent strains in the genus Pasteurella, which was first suggested by Pohl (15), is not surprising since close genetic relationships between $\mathrm{V}$-factor-dependent and $\mathrm{V}$-factor-independent taxa have been described for the Actinotiacillus lignieresii-Haemophilus pleuropneumoniae group $(15,17)$ and for the Haemophilus aphrophilus-Haemophilus paraphrophilus group (15). These observations indicate that V-factor dependency is not

TABLE 4. Levels of DNA relatedness of $P$. volantium strain NCTC $3438^{\mathrm{T}}$ with selected members of the Pasteurellaceae

\begin{tabular}{|c|c|c|}
\hline Species & Strain & $\begin{array}{c}\% \text { Homology with strain } \\
\text { NCTC } 3438^{\mathrm{T}} \\
\text { (unless otherwise stated) }\end{array}$ \\
\hline P. volantium & NCTC $3438^{\mathrm{T}}$ & 100 \\
\hline P. volantium & HIM 789-3 & $90(5.7)^{a}$ \\
\hline P. volantium & NCTC 4101 & $81(7.4)^{b}$ \\
\hline P. gallinarum & ATCC $13361^{\mathrm{T}}$ & $72(7.9)$ \\
\hline P. gallinarum & ATCC 13360 & $70(8.1)$ \\
\hline P. avium & ATCC $29546^{\mathrm{T}}$ & $60(3.0)^{c}$ \\
\hline P. multocida & NCTC $10322^{\mathrm{T}}$ & $59(4.9)$ \\
\hline Pasteurella sp. & NCTC 11411 & $49(5.2)^{d}$ \\
\hline Pasteurella sp. & NCTC 11624 & $42(11.4)$ \\
\hline Pasteurella species A & HIM 789-5 & $35(10.6)^{e}$ \\
\hline Pasteurella species A & HIM 789-1 & $35(7.8)$ \\
\hline H. paragallinarum & ATCC $29545^{\mathrm{T}}$ & $35(16.8)$ \\
\hline Pasteurella sp. & HIM $745-4$ & $33(5.8)$ \\
\hline Pasteurella sp. & HIM $789-6$ & $28(8.4)^{f}$ \\
\hline H. parainfluenzae & NCTC $7857^{\mathrm{T}}$ & $18(3.6)^{g}$ \\
\hline
\end{tabular}

${ }^{a}$ The values in parentheses are standard deviations.

${ }^{b}$ When Pasteurella volantium strain HIM 789-3 was tested instead of strain NCTC $3438^{\mathrm{T}}$, the level of DNA homology was $88 \%$ (standard deviation, $3.1 \%$ ).

"When $P$. volantium strain HIM 789-3 was tested instead of strain NCTC

$3438^{\mathrm{T}}$, the level of DNA homology was $44 \%$ (standard deviation, $9.3 \%$ )

${ }^{d}$ When $P$. rolantium strain HIM 789-3 was tested instead of strain NCTC $3438^{\mathrm{T}}$, the level of DNA homology was $57 \%$ (standard deviation, $4.6 \%$ ).

"When $P$. volantium strain HIM 789-3 was tested instead of strain NCTC

$3438^{\mathrm{T}}$, the level of DNA homology was $35 \%$ (standard deviation, $4.7 \%$ ).

$f$ Tested with $P$. volantium strain HIM $789-3$ instead of strain NCTC $3438^{\mathrm{T}}$.

${ }^{s}$ Tested with $P$. volantium strain NCTC 4101 instead of strain NCTC $3438^{\mathrm{T}}$
TABLE 5. Levels of DNA relatedness of Pasteurella species A strain HIM 789-5 with selected members of the Pasteurellaceae

\begin{tabular}{|c|c|c|}
\hline Species & Strain & $\begin{array}{l}\text { \% Homology with strain } \\
\text { HIM 789-5 } \\
\text { (unless otherwise stated }\end{array}$ \\
\hline Pasteurella species A & HIM 789-5 & 100 \\
\hline Pasteurella species A & HIM $789-2$ & $91(7.0)^{a}$ \\
\hline Pasteurella species A & HIM 789-1 & $83(4.4)$ \\
\hline Pasteurella sp. & HIM 789-6 & $66(7.8)^{b}$ \\
\hline$P$. gallinarum & ATCC $13361^{\mathrm{T}}$ & $63(5.2)^{c}$ \\
\hline H. paragallinarum & ATCC $29545^{\mathrm{T}}$ & $36(7.6)$ \\
\hline Pasteurella sp. & NCTC 11411 & $26(1.4)^{d}$ \\
\hline Pasteurella sp. & NCTC 11623 & $24(9.1)$ \\
\hline P. multocida & NCTC $10322^{\mathrm{T}}$ & $19(11.7)$ \\
\hline P. multocida & SSI P614 & $3(0.7)$ \\
\hline Haemophilus sp. & HIM $716-7$ & $1(3.5)$ \\
\hline H. parainfluenzae & HIM $793-8$ & $0(1.4)$ \\
\hline Haemophilus somnus & HIM $734-5$ & $0(4.2)$ \\
\hline Haemophilus sp. & HIM $716-4$ & $0(6.4)$ \\
\hline Haemophilus sp. & HIM $700-8$ & $0(8.0)$ \\
\hline H. aphrophilus & NCTC $5906^{\mathrm{T}}$ & $0(7.1)$ \\
\hline $\begin{array}{l}\text { Actinobacillus } \\
\text { pleuropneumoniae }\end{array}$ & $\operatorname{CCM} 5869^{\mathrm{T}}$ & $0(7.8)$ \\
\hline H. influenzae & NCTC $8143^{\mathrm{T}}$ & $0(11.5)$ \\
\hline
\end{tabular}

"The values in parentheses are standard deviations.

${ }^{b}$ When Pasteurella species A strain HIM 789-1 was tested instead of strain HIM 789-5, the level of DNA homology was $58 \%$ (standard deviation, $7.8 \%$ ).

When Pasteurella species A strain HIM 789-1 was tested instead of strain HIM 789-5, the level of DNA homology was $67 \%$ (standard deviation, $6.6 \%$ ); when Pasteurella species A strain HIM 789-2 was used, the level of DNA homology was $63 \%$ (standard deviation, $9.5 \%$ ).

d Tested with Pasteurella species A strain HIM 789-1 instead of strain HIM 789-5. When Pasteurella species A strain HIM 789-2 was tested instead of strain HIM 789-1, the level of DNA homology was $18 \%$ (standard deviation, $4.7 \%)$.

a generic feature of Haemophilus but is a common feature among various members of the family Pasteurellaceae. Considering the foregoing, two new Pasteurella species are proposed, as described below.

Pasteurella avium (Hinz and Kunjara) comb. nov. P . avium contains V-factor-dependent strains hitherto classified as Haemophilus avium and V-factor-independent strains classified as the ornithine decarboxylase-negative type of Bisgaard taxon 13. The cells are gram-negative, coccoid, nonsporeforming rods which occur singly or in short chains. They are mesophilic, chemoorganotrophic, facultatively aerobic, and fermentative. Ubiquiones and demethylmenaquinones are produced. Oxidase, catalase, and alkaline phosphatase reactions are positive. Nitrates are reduced to nitrites. No growth occurs on MacConkey agar and in Simmons citrate medium. The surface colonies on chocolate agar are smooth, convex, and grayish white. On sheep blood agar supplemented with NAD no hemolysis occurs. Acid is produced from D-glucose without gas formation and from D-galactose, D-mannose, D-fructose, sucrose, and trehalose. No acid is produced from L-sorbose, L-arabinose, Lrhamnose, starch, raffinose, maltose, mannitol, sorbitol, $m$-inositol, adonitol, or dulcitol. Some strains produce acid from D-xylose. Negative reactions are obtained for indole production, hydrolysis of urea and arginine, decarboxylation of lysine and ornithine, and liquefaction of gelatin. Found in the hearts and infraorbital sinuses of chickens and in the lungs of calves suffering from pneumonia. The $\mathrm{G}+\mathrm{C}$ content of the DNA is 43 to $45 \mathrm{~mol} \%$. The genome molecular weight is $1.9 \times 10^{9}$. Strain IPDH $2654(=$ ATCC 29546) is the type strain.

Description of the type strain. The type strain has all of the characteristics given above for the species. It does not 
produce acid from D-xylose and was isolated from a chicken (6).

Pasteurella volantium sp. nov. Pasteurella volantium (vo.lan'ti.um. L. fem. gen. pl. n. volantium from fowl) cells are gram-negative, immotile, coccoid, nonsporeforming rods which occur singly or in short chains. They are mesophilic, chemoorganotrophic, facultatively aerobic, fermentative, and V-factor dependent. Oxidase, catalase, and alkaline phosphatase reactions are positive. Ubiquinones and demethylmenaquinones are produced. Nitrates are reduced to nitrites. No growth occurs on MacConkey agar or on Simmons citrate medium. On chocolate agar the surface colonies are smooth and convex and may produce yellowish pigments. On sheep blood agar supplemented with NAD no hemolysis occurs. The phenotypic features of $P$. volantium are similar to those of $P$. avium, but $P$. volantium differs in being maltose and mannitol positive and often sorbitol positive. Ornithine is decarboxylated by some strains. The $\mathrm{G}+\mathrm{C}$ content is 44 to $45 \mathrm{~mol} \%$. The genome molecular weight is $1.5 \times 10^{9}$ to $1.9 \times 10^{9}$. Found in the wattles of domestic fowl. One strain has been isolated from a human tongue (7). The type strain is strain Lovell $6(=$ NCTC $3438=$ ATCC 14385$)$.

Description of the type strain. The type strain has all of the characteristics of the species. In addition, it produces acid from D-xylose but not from sorbitol or lactose. Ornithine is not decarboxylated. This strain was isolated from a chicken.

Although a third group of former $H$. avium strains was included in the genus Pasteurella on the basis of DNA homology, it appeared to be heterogeneous (Table 2) and should be described when more strains have been studied. We suggest strain IPDH 280 (HIM 789-5) as a reference strain for this species, provisionally named Pasteurella species A.

\section{LITERATURE CITED}

1. Bisgaard, M. 1982. Isolation and characterization of some previously unreported taxa from poultry with phenotypical characters related to Actinobacillus and Pasteurella species. Acta Pathol. Microbiol. Immunol. Scand. Sect. B. 90:59-67.

2. De Ley, J., H. Cattoir, and A. Reynaerts. 1970. The quantitative measurement of DNA hybridization from renaturation rates. Eur. J. Biochem. 12:133-142.

3. Gillis, M., J. De Ley, and M. De Cleene. 1970. The determination of molecular weight of bacterial genome DNA from renaturation rates. Eur. J. Biochem. 12:143-153.

4. Hinz, K.-H. 1973. Beitrag zur Differenzierung von HaemophilusStämmen aus Hühnern. I. Mitteilung: Kulturelle and biochemische Untersuchungen. Avian Pathol. 3:211-229.
5. Hinz, K.-H. 1975. Beitrag zur Differenzierung von HaemophilusStämmen aus Hühnern. III. Mitteilung: Pathogenitätsprüfungen an Hühnerküken. Avian Pathol. 4:213-226.

6. Hinz, K.-H., and C. Kunjara. 1977. Haemophilus avium, a new species from chickens. Int. J. Syst. Bacteriol. 27:324-329.

7. Kilian, M. 1976. A taxonomic study of the genus Haemophilus, with the proposal of a new species. J. Gen. Microbiol. 93:9-62.

8. Kilian, M., and W. Frederiksen. 1981. Identification tables for the Haemophilus-Pasteurella-Actinobacillus group, p. 281-290. In M. Kilian, W. Frederiksen, and E. L. Biberstein (ed.), Haemophilus, Pasteurella, and Actinobacillus. Academic Press, Inc., London.

9. Mannheim, W. 1966. Limitierende Faktoren in Mischkulturen eines obligaten Aerobiers (Achromobacter metalcaligenes) mit Haemophilus influenzae resp. mit Anaerobiern. Pathol. Microbiol. 29:341-365.

10. Mannheim, W. 1981. Taxonomic implications of DNA relatedness and quinone patterns in Actinobacillus, Haemophilus, and Pasteurella, p. 265-280. In M. Kilian, W. Frederiksen, and E. L. Biberstein (ed.), Haemophilus, Pasteurella, and Actinobacillus. Academic Press, Inc., London.

11. Mannheim, W. 1984. Family Pasteurellaceae Pohl 1981, p. 550-552. In N. R. Krieg and J. G. Holt (ed.), Bergey's manual of systematic bacteriology, vol. 1. The Williams \& Wilkins Co., Baltimore.

12. Mannheim, W., S. Pohl, and R. Holländer. 1980. Zur Systematik von Actinobacillus, Haemophilus and Pasteurella: Basenzusammensetzung der DNS, Atmungschinone and kulturell-biochemische Eigenschaften repräsentativer Sammlungsstämme. Zentralbl. Bakteriol. Parasitenkd. Infektionskr. Hyg. Abt. 1 Orig. Reihe A 246:512-540.

13. Mutters, R., W. Frederiksen, and W. Mannheim. 1984. Lack of evidence for the occurrence of Pasteurella ureae in rodents. Vet. Microbiol. 9:83-93.

14. Mutters, R., K. Piechulla, and W. Mannheim. 1984. Phenotypic differentiation of Pasteurella sensu stricto and the Actinobacillus group. Eur. J. Clin. Microbiol. 3:225-229.

15. Pohl, S. 1981. DNA relatedness among members of Haemophilus, Pasteurella and Actinobacillus, p. 245-253. In M. Kilian, W. Frederiksen, and E. L. Biberstein (ed.), Haemophilus Pasteurella, and Actinobacillus. Academic Press, Inc., London.

16. Pohl, S. 1981. Validation of the publication of new names and new combinations previously published outside the IJSB. Int. J. Syst. Bacteriol. 31:382-383.

17. Pohl, S., M. V. Bertschinger, W. Frederiksen, and W. Mannheim. 1983. Transfer of Haemophilus pleuropneumoniae and the Pasteurella haemolytica-like organism causing porcine necrotic pleuropneumonia to the genus Actinobacillus (Actinobacillus pleuropneumoniae comb. nov.) on the basis of phenotypic and deoxyribonucleic acid relatedness. Int. J. Systm. Bacteriol. 33:510-514. 